\title{
A Confiança do Usuário na Administração de Dados da Dataprev
}

\author{
Magali Granja Coutinho ${ }^{1}$ \\ José Roberto Ribas ${ }^{2}$ \\ Paulo Roberto da Costa Vieira ${ }^{3}$
}

\section{Resumo}

A qualidade da informação tem despertado interesse crescente dos estudiosos da área de negócios, por se tratar de uma peça fundamental na tomada de decisão em todos os níveis da gestão corporativa. Recomenda-se, portanto, em pensar no seu conceito não como um meio, da forma como é geralmente concebida, mas sim como um produto. Neste estudo, enfatiza-se a necessidade dos gestores por indicadores que possibilitem avaliar a maneira pela qual a informação é percebida em função de seu uso, seu valor e sua confiabilidade. Desse modo, o objetivo deste estudo é verificar se a confiança do usuário interno é influenciada pela qualidade e pelo valor percebido da informação prestada pela área de Administração de Dados. A pesquisa tipo survey foi realizada na Dataprev, empresa pública de tecnologia da informação a serviço da previdência social. A amostra não aleatória foi constituída por 108 respondentes, cujos dados foram coletados por meio de um questionário estruturado contendo 14 questões medidas por uma escala Likert com cinco pontos, os quais foram tratados com uma Modelagem de Equações Estruturais (MEE). Constatou-se que o construto Qualidade da Informação é um antecedente significativo para o Valor Percebido, o qual atua como construto mediador para com a Confiança em relação à informação. Confirmou-se, ademais, a adequação da MEE às questões que envolvam relações causais entre variáveis latentes.

Palavras-chave: Qualidade da Informação. Confiabilidade. Gestão Corporativa.

${ }^{1}$ Doutoranda pela Universidade Federal Fluminense - UFF. Administradora de Dados Sênior da Dataprev. End.: Rua Prof. Álvaro Rodrigues, 460, Botafogo-RJ. CEP: 22280-040-Brasil.E-mail: magali.coutinho@previdencia.gov.br.

${ }^{2}$ Doutor pela Escola de Administração de Empresas da Fundação Getúlio Vargas. Professor Adjunto da Escola Politécnica da Universidade Federal do Rio de Janeiro - UFRJ. End.: Centro de Tecnologia, Bloco F, Sala 101, Cidade Universitária, Rio de Janeiro - RJ. CEP: 21941-909-Brasil. Email: ribas@poli.ufrj.br.

${ }^{3}$ Doutor pela COPPE/Universidade Federal do Rio de Janeiro. Professor do Mestrado em Administração e Desenvolvimento Empresarial da Universidade Estácio de Sá-UNESA. End.: Av. Presidente Vargas, 642,22ªndar, Centro, Rio de Janeiro-RJ. CEP: 20071-001 - Brasil. E-mail: paulorcv@bcb.gov.br. Artigo recebido em: 15/12/2009. Aceito em: 16/02/2011. Membro do Corpo Editorial Científico responsável pelo processo editorial: Martinho Isnard Ribeiro de Almeida

(c) (i) () $\bigodot_{\text {EY NC No }}$ Esta obra está sob uma Licença Creative Commons Atribuição-Uso. 


\section{Introdução}

Na linha de reflexão desenvolvida por Barbieri (2001) sobre a Evolução de Dados e Sistemas, procurou-se elucidar as relações relevantes entre informação, organização e tomada de decisão, tendo como referência histórica, a revolução da informação. Segundo Barbieri (2001, p. 2), no passado "[...] os dados até então, eram na realidade, meros coadjuvantes de um processo de desenvolvimento de sistemas, onde o empirismo metodológico de muitos e a aspiração de alguns definiam os caminhos a trilhar". Nos anos 80 , a partir do surgimento de novas metodologias, a exemplo da modelagem, análise de dados e da engenharia da informação, ocorreu uma descontinuidade no estilo "processual" mantido até então. Ainda assim, a orientação tinha profundas raízes tecnológicas, em detrimento da ênfase nos negócios. Os anos 90 chegaram para confirmar os vaticínios dos anos 70 . Com os dados atingindo o status de objeto e o casamento tecnológico entre informação e comunicação festejando em todas as esquinas do planeta, a nossa sociedade começou a fazer uma plástica cultural definitiva. Diferentemente da Revolução Industrial, em que as benesses não chegavam a todos diretamente, a revolução dos dados e das informações, capitaneada pela internet, tornou-se democrática, evasiva e de amplo alcance.

A informação e o conhecimento são essencialmente criações humanas, assim, nunca seremos capazes de administrá-los sem levarmos em consideração o papel fundamental desempenhado pelas pessoas (DAVENPORT, 1998). A informação e o conhecimento estão, gradualmente, se tornando os principais geradores de valor e riqueza, chegando a ter a mesma ou maior importância do que os recursos naturais, os equipamentos e o capital (STEWART, 1998). As organizações do Século XXI devem aproveitar o potencial de seus dados, utilizando-os de modo competitivo para alcançar seus objetivos estratégicos (WANG; LEE; HUANG, 1998). O impacto da informação é medido por seu poder em satisfazer o usuário, desde o momento inicial quando se decide por utilizá-la, até momentos posteriores quando se pondera se a informação adquirida está ou não adequada às necessidades.

Na medida em que a organização se preocupa em mapear o resultado de sua atuação como prestadora de serviço e produto, ela ampliará o conhecimento necessário para aprimorar seus processos e poderá utilizá-lo para manter e melhorar a qualidade de seu produto principal - a informação. Para atingir tal objetivo, é fundamental que os administradores e gerentes da or- 
ganização tenham uma visão correta do seu uso. Davenport (1998, p. 194) afirma que "[...] a informação de nada servirá até que seja utilizada. O uso é a etapa final de todo processo de gerenciamento informacional, mas até mesmo pesquisadores e gerentes da área o têm ignorado".

O objetivo principal deste estudo é verificar, com o auxílio da modelagem de equações estruturais, se a confiança do usuário interno é influenciada pela qualidade e pelo valor percebido da informação prestada pela área de Administração de Dados, através da especificação de um modelo que se propõe a capturar tais influências. Entende-se por usuário interno os analistas de sistemas que trabalham nos projetos da empresa e que utilizam os serviços da área mencionada. O usuário externo, por sua vez, compreende os analistas de sistemas de outras instituições públicas federais que utilizam esses mesmos serviços, a exemplo do INSS, Ministério do Trabalho e Emprego e Receita Federal do Brasil. A Dataprev - Empresa de Tecnologia e Informações da Previdência Social é uma empresa pública vinculada ao Ministério da Previdência Social e tem por objetivo estudar e viabilizar tecnologias de informática na área da Previdência Social. Essa Empresa é responsável pelo processamento da maior folha de pagamento do país, alcançando mais de 20 milhões de beneficiários/mês.

\section{Referencial Teórico}

\subsection{Percepção da Informação}

A percepção é o processo pelo qual o receptor é exposto à informação, presta atenção, compreende e se envolve. No estágio de exposição, os usuários recebem a informação através dos seus sentidos; no estágio de atenção, eles se concentram em um estímulo e; no estágio de compreensão, eles o organizam e o interpretam a fim de captar o seu significado. Entende-se, portanto, que a percepção é influenciada pela qualidade da comunicação entre o gestor, o usuário e pela intensidade de envolvimento manifestada por este último. No primeiro aspecto, um dos maiores problemas observados é o de que "[...] infelizmente, as pessoas que administram a tecnologia da informação [...] têm pouca paciência com as necessidades dos usuários" (DAVENPORT, 1998, p. 12). Quanto ao envolvimento, Mowen e Minor (2003, p. 45) o conceituam como sendo "[...] a importância percebida ou o 
interesse pessoal em relação à aquisição, ao consumo e à disposição de uma mercadoria, serviço ou idéia". Para eles, a interpretação e o significado das informações recebidas podem ocorrer de maneiras diferentes para pessoas diferentes, mesmo quando os estímulos forem iguais. Isso porque a capacidade de entender a informação é influenciada por expectativas e experiências anteriores. Sendo que "[...] as expectativas do usuário aumentam à medida que estes se interam da disponibilidade e da qualidade dos produtos $e$ serviços" (TURBAN et al, 2006, p. 6).

\subsection{Valor Percebido}

Anderson e Narus (1998) e Gale (2000a, 2000b) propõem uma visão mais racional para valor percebido, baseada na recompensa ou na penalização monetária atribuída pelo mercado. Nesse caso, o valor percebido poderia ser mensurável a partir da diferença de preço, ou do prêmio que os consumidores estariam dispostos a pagar para ter acesso aos benefícios oferecidos por um produto ou serviço. Ravald e Gronroos (1996), Gronroos (2003) e Oliver (1999) sugerem, a partir de uma visão utilitarista, que o valor percebido resulta de uma relação entre benefícios e sacrifícios onde, na qual o numerador contém as recompensas que o consumidor percebe como proporcionadas pelo produto e, no denominador, os sacrifícios: monetário, psicológico e de relacionamento. Para os primeiros autores, os elementos de um relacionamento podem ser detectados e eliminados, no caso de serem destrutivos, ou localizados e reforçados, se aprimoradores de valor. Assim, pode-se deduzir que o valor total percebido pelo cliente representa a relação entre os somatórios dos benefícios e dos sacrifícios de episódios, os quais são potencializados, para melhor ou para pior, a partir dos reflexos de um relacionamento contínuo.

A informação, como qualquer outro recurso de uma organização, representa uma unidade de valor. Sob a ótica dos sacrifícios, agregar valor à informação não significa apenas agregar benefícios (BARRETO, 1999). De nada adianta reformular e classificar uma informação se, para obtê-la, o usuário necessita transitar por canais de difícil comunicação em que o relacionamento com a fonte nem sempre é fácil e objetivo, difícultando assim o seu acesso. Desse modo, a maximização do valor percebido pelo cliente não ocorre a partir da simples incorporação de benefícios adicionais, sujeitos a uma rápida assimilação pela concorrência, mas sim a partir da redução nos sacri- 
fícios decorrentes, a exemplo da maior facilidade de acesso ao produto ou ao serviço (RAVALD; GRONROOS, 1996).

"Um modo muito eficaz de agregar valor para os clientes é melhorar o que já é feito para eles, em vez de criar algo de novo" (GRONROOS, 2003, p. 181). As equipes de apoio podem refinar a exatidão da informação, descobrindo quais são as fontes valorizadas e consideradas como confiáveis pelos usuários, confirmando regularmente a exatidão e gerando um programa de qualidade destinado à transação de dados relevantes. Uma vez que a informação é qualificada como um instrumento modificador da consciência e da sociedade como um todo (BARRETO, 1994), essa informação apenas resultará em conhecimento se for percebida e aceita, colocando a pessoa em um estágio superior de convivência, estimulando assim o comportamento inovador. Pode-se concluir, dessa maneira, que o usuário somente conseguirá perceber o valor da informação recebida se ele assimilar o seu significado.

\subsection{A Qualidade da Informação}

Neste estudo, a qualidade do produto informação é avaliada de acordo com a sua capacidade de satisfazer às necessidades dos usuários. Há um número amplo de pesquisas com enfoque na satisfação do usuário com a tecnologia da informação ou com a qualidade do serviço prestado, a exemplo do procedimento denominado por Servqual (apud PARASUMARAN, ZEITHAML; BERRY; 1988) e dos procedimentos para mensuração da satisfação do usuário de Doll e Torkzadeh (1998).

Segundo essa ótica, é possível estabelecer uma correspondência entre os itens do instrumento de medida de satisfação, conforme identificados a partir do trabalho desenvolvido por Sebera e Tan (2005), com as dimensões da qualidade da informação listadas a partir de Wang, Lee e Huang (1998), cujo resultado pode ser observado na Tabela 1. 
Tabela 1: Comparação entre medida de satisfação e qualidade da informação

\begin{tabular}{|c|c|}
\hline $\begin{array}{c}\text { Itens do instrumento de medida de } \\
\text { satisfação de Sebera e Tan (2005) }\end{array}$ & $\begin{array}{c}\text { Dimensões da qualidade da informa- } \\
\text { ção de Wang, Lee e Huang (1998) }\end{array}$ \\
\hline Precisão da informação de saída & Acurácia (categoria intrínseca) \\
\hline Tempestividade da informação de saída & Tempestividade (categoria contextual) \\
\hline Credibilidade da informação de saída & Credibilidade (categoria intrínseca) \\
\hline Atualidade da informação de saída & Tempestividade (categoria contextual) \\
\hline Completitude da informação de saída & Completude (categoria contextual) \\
\hline Formato da informação de saída & Facilidade de entendimento(categoria \\
\hline Volume da informação de saída & Quantidade (categoria contextual) \\
\hline Segurança de dados e de modelos & Segurança (categoria acessibilidade) \\
\hline
\end{tabular}

Fonte: Adaptada de Sebera e Tan (2005) e de Wang, Lee e Huang (1998)

São quatro os princípios para assegurar a qualidade da informação: (a) entender quais são as informações que os usuários precisam; (b) gerenciar a informação como um produto oriundo de um processo de produção bem definido; (c) gerenciar a informação como um produto que possui um ciclo de vida; (d) designar um gerente de informação para controlar os processos e seus resultados (WANG; LEE; HUANG, 1998). As características da qualidade da informação estão além dessa dimensão. Para avaliá-la em sua totalidade, Wang, Lee e Huang (1998) a classificam segundo quatro categorias e 15 dimensões, conforme a Tabela 2.

Tabela 2: Categorias e Dimensões da Qualidade da Informação

\begin{tabular}{|c|c|l|}
\hline \multicolumn{1}{|c|}{ Categoria } & Dimensão & \multicolumn{1}{|c|}{ Descrição da dimensão } \\
\hline \multirow{4}{*}{ Qualidade Intrínseca } & $\begin{array}{c}\text { Acurácia } \\
\text { (exatidão })\end{array}$ & Dado exato, preciso; sem erro. \\
\cline { 2 - 3 } & Objetividade & $\begin{array}{l}\text { Dado claro, não ambíguo, imparcial e inde- } \\
\text { pendente. }\end{array}$ \\
\cline { 2 - 3 } & Credibilidade & Dado verdadeiro e confiável. \\
\cline { 2 - 3 } & Reputação & Fonte de dados e conteúdo confiáveis. \\
\hline
\end{tabular}

Fonte: Adaptado de Wang, Lee e Huang (1998) 
Tabela 2: Categorias e Dimensões da Qualidade da Informação

\begin{tabular}{|c|c|c|}
\hline Categoria & Dimensão & Descrição da dimensão \\
\hline \multirow{2}{*}{$\begin{array}{l}\text { Qualidade de } \\
\text { Acessibilidade }\end{array}$} & Acessibilidade & Dado disponível; recuperação fácil para uso. \\
\hline & Segurança & $\begin{array}{l}\text { Dado de acesso restrito, armazenamento } \\
\text { seguro e confiável. }\end{array}$ \\
\hline \multirow{5}{*}{$\begin{array}{l}\text { Qualidade } \\
\text { Contextual }\end{array}$} & Relevância & Dado aplicável e útil na sua finalidade de uso \\
\hline & Valor agregado & $\begin{array}{l}\text { Dado adiciona benefícios e vantagens com } \\
\text { sua utilização. }\end{array}$ \\
\hline & Atualização & Dado atualizado e entregue no tempo certo. \\
\hline & Completude & $\begin{array}{l}\text { Dado suficiente em escopo e completo para } \\
\text { uso. }\end{array}$ \\
\hline & Quantidade & Dado com quantidade adequada ao uso. \\
\hline \multirow{4}{*}{$\begin{array}{l}\text { Qualidade } \\
\text { Representacional }\end{array}$} & Interpretabilidade & $\begin{array}{l}\text { Dado com linguagem, simbologia, unidade e } \\
\text { clareza apropriadas ao uso e receptores. }\end{array}$ \\
\hline & $\begin{array}{l}\text { Facilidade de } \\
\text { entendimento }\end{array}$ & Dado facilmente compreendido. \\
\hline & $\begin{array}{l}\text { Consistência de } \\
\text { representação } \\
\text { (integridade) }\end{array}$ & $\begin{array}{l}\text { Dado apresentado sempre com o mesmo } \\
\text { conteúdo; deve haver compatibilidade entre o } \\
\text { dado atual e o dado histórico. }\end{array}$ \\
\hline & $\begin{array}{l}\text { Representação } \\
\text { concisa }\end{array}$ & $\begin{array}{l}\text { Dado representado de forma compacta e } \\
\text { resumida. }\end{array}$ \\
\hline
\end{tabular}

Fonte: Adaptado de Wang, Lee e Huang (1998)

A categoria intrínseca baseia-se em aspectos objetivos e refere-se à característica interna da informação. As categorias contextual, representacional e de acessibilidade, relacionam-se à utilização, e a característica das suas dimensões é subjetiva. A categoria contextual diz respeito às condições e às circunstâncias nas quais a informação é utilizada, a representacional está relacionada com as regras pré-definidas nos sistemas de informação ou da política de divulgação e disseminação. Já a categoria de acessibilidade é referente aos aspectos da segurança e contato com a informação, utilizando-se dos recursos disponíveis da tecnologia da informação e dos planos de segurança e contingência da organização.

A mensuração do ciclo de gerenciamento da informação proposto por Wang, Lee e Huang (1998) sugere que inicialmente as dimensões acurácia, 
tempestividade, completude e consistência de representação sejam selecionadas para a definição das métricas para mensuração da qualidade. Nessa fase, algumas regras para validação são definidas. Encontram-se na Tabela 3 exemplos das dimensões e suas respectivas regras de validação. Observa-se, na prática, problemas comuns de qualidade com base nas categorias e nas dimensões da qualidade da informação, a saber:

a) Categoria intrínseca: diversas fontes de dados para atualização de uma ou um conjunto de informações.

b) Categoria contextual: problemas na digitação e coleta de dados, evolução dos sistemas com a implementação de novas regras sem a preocupação (ou na impossibilidade) de ajuste dos dados já existentes nas bases de dados, gerando lacunas e inconsistências.

c) Categoria representacional: no momento da utilização da informação, a partir da maneira como ela é apresentada ao usuário, muitas vezes de forma ambígua ou de difícil compreensão, encontra-se, com frequência, o uso incorreto pelo usuário.

d) Categoria de acessibilidade: originam-se de problemas nos recursos tecnológicos utilizados, tais como rede, software gerenciador do banco de dados, senhas e acessos, além da eficiência da política de segurança da organização.

Tabela 3: Regras de validação para as dimensões da qualidade da informação

\begin{tabular}{|c|l|}
\hline Dimensão & \multicolumn{1}{c|}{ Exemplo } \\
\hline Acurácia & $\begin{array}{l}\text { CPF: pode conter somente números; } \\
\text { Nome: não pode conter três dígitos iguais sequencialmente; e } \\
\text { Data: o valor máximo para dia deverá ser 31, o valor para mês deverá ser } \\
\text { 12, conforme as regras estabelecidas para os anos de calendário. }\end{array}$ \\
\hline Tempestividade & $\begin{array}{l}\text { Dado volátil: estado civil, endereço, grau de instrução - estabelecer a } \\
\text { frequência para atualização do dado: quinzenal, anual; e } \\
\text { Dado não volátil: sexo, data de nascimento e filiação. }\end{array}$ \\
\hline Completude & $\begin{array}{l}\text { Data: as posições relativas ao dia, mês ao ano devem ser de preenchi- } \\
\text { mento obrigatório; } \\
\text { Nome: deve conter no mínimo duas sequências de caracteres válidas; e } \\
\text { CPF: deve conter no mínimo 11 dígitos. }\end{array}$ \\
\hline $\begin{array}{c}\text { Consistência de } \\
\text { representação }\end{array}$ & $\begin{array}{l}\text { Data: apresentar sempre a informação baseada em uma regra de formação } \\
\text { da data pré-definida - aaaa/mm/dd, dd-mm-aaaa, dd/mm/aa, dd/mmm/aaaa. }\end{array}$ \\
\hline
\end{tabular}

Fonte: Elaborada pelos autores 
Constata-se, então, que não é qualquer informação que agrega valor, já que a informação valiosa é aquela utilizada para alavancar e continuar os negócios da organização, ou seja, aquela que possui qualidade superior.

Há duas definições significativas para a qualidade da informação. Uma é a inerente, e a outra é a pragmática. Qualidade de informação inerente é a exatidão ou acurácia dos dados. Qualidade da informação pragmática é o valor que dados acurados possuem no suporte de trabalhos do empreendimento. Dados que não ajudam a possibilitar ao empreendimento atingir sua missão não possuem qualidade, não importando quão acurados sejam (ENGLISH, 1999, p. 25).

Na visão do autor, informações simplesmente armazenadas, por mais corretas que sejam, apenas serão úteis a partir do momento que forem utilizadas no processo administrativo ou decisório do empreendimento, essa é a característica pragmática do dado. A informação que representa valor é aquela que resulta em alguma ação, ou seja, o valor é sinônimo de utilidade programática. Destaca-se, neste item do estudo, que a falta de qualidade da informação faz com que as organizações percam oportunidades e clientes, tomem decisões incertas, operem com ineficiência, além de aumentar sua despesa com os ajustes e prejuízos assumidos.

\subsection{Confiança em Relação à Informação}

O que importa realmente é o cultivo de um bom relacionamento com o cliente para poder estar mais próximo dele. As estatísticas demonstram que um cliente satisfeito fala de sua satisfação com outras cinco pessoas, e o insatisfeito o faz com nove outros (BARBIERI, 2001). Essa é a ótica da cadeia dos formadores de opinião. Coleman (1990, p. 304), ressalta que "[...] o conjunto das relações sociais em que um indivíduo se encontra inserido é que o ajudam a atingir objetivos que, sem tais relações, seriam inalcançáveis ou somente alcançáveis a um custo mais elevado". A confiança de um indivíduo com relação a um parceiro em potencial é uma dimensão resultante de um processo duradouro que acaba por refletir na confiabilidade deste parceiro (SHEPPARD; SHERMAN, 1998), e apenas ocorre porque eles acreditam que 
os interesses são comuns às partes envolvidas (HARDIN, 2001). Essa definição contribui para a compreensão do modo como as relações de confiança surgem. Pode-se concluir, então, que a confiança é uma medida subjetiva baseada na expectativa e em experiências anteriores e, além disso, depende da relação entre as pessoas, bem como das normas e regulamentos que as cercam.

\section{Método}

A natureza da presente pesquisa é descritiva com uma abordagem quantitativa. Pretende-se avaliar o grau de confiança do usuário, considerando suas percepções sobre as informações prestadas quanto à qualidade e quanto ao valor percebido. Além da pesquisa bibliográfica foram consultados, também, os especialistas da área de Administração de Dados, profissionais de TI, administradores, auditores, gerentes e usuários internos.

Na medida em que foi construído um modelo causal, no qual ocorrem variáveis latentes dependentes e independentes que não podem ser diretamente observadas, julgou-se apropriado o emprego da Modelagem de Equações Estruturais, não apenas para avaliação empírica da pesquisa, mas, também, para a identificação dos impactos mais significativos sobre a confiança (variável latente dependente).

A população é constituída pelos usuários internos da área de Administração de Dados da Dataprev, localizados na sede da empresa e nas filiais distribuídas pelas capitais do país. Cabe salientar, que não há, necessariamente, usuários em todas as filiais. A partir da lista de distribuição do correio eletrônico do administrador, da qual participaram 315 usuários, identificouse a população da pesquisa. Um questionário estruturado foi colocado na intranet em setembro de 2006, e toda a população foi convidada para participar da pesquisa por meio de correspondência enviada pelo gerente da área de Administração de Dados aos seus respectivos endereços eletrônicos. $\mathrm{O}$ número de respondentes qualificados que responderam ao questionário expontâneamente, e cujas respostas foram validadas, atingiu 108 participantes.

Utilizando-se a Modelagem de Equações Estruturais, objetivou-se verificar se a confiança do usuário interno na informação prestada pela área de Administração de Dados é influenciada pela qualidade da informação. Para isso, foram estabelecidas as seguintes hipóteses fundamentais: 
H1: A variável latente Valor Percebido é influenciada direta e positivamente pela variável latente Qualidade da Informação.

H2: A variável latente Confiança é influenciada direta e positivamente pela variável latente Valor Percebido.

H3: A variável latente Confiança é influenciada direta e positivamente pela variável latente Qualidade da Informação.

O Diagrama de Caminho da Figura 1 ilustra o modelo estrutural que será testado na pesquisa. A variável Qualidade da Informação (QUALINF) é exógena, antecedendo Valor Percebido (VALPERF) e Confiança (CONFIAN), sendo esta última endógena e precedida por VALPERF.

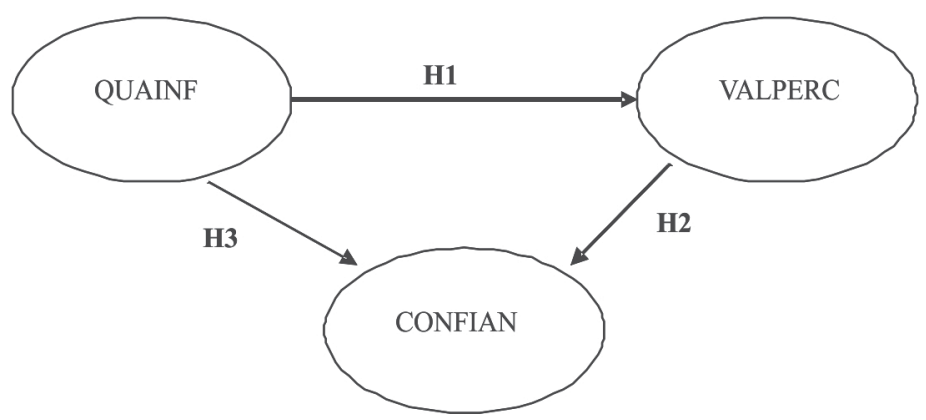

Figura 1: Diagrama de Caminho do Modelo Estrutural

Fonte: Elaborada pelos autores

Na especificação das variáveis desta pesquisa, levou-se em consideração a revisão da literatura, bem como a verificação de que as variáveis utilizadas estavam isentas de erros de mensuração e de resíduos intercorrelacionados. Ademais, o fluxo observado na especificação do modelo deve ser unidirecional (SCHREIBER at al., 2006), o tamanho da amostra significativo, bem como a ocorrência de normalidade multivariada (RIBAS; VIEIRA, 2011). As Tabelas 4, 5 e 6 apresentam as variáveis observadas dos construtos QUAINF, CONFIAN e VALPERC, respectivamente: 
Tabela 4: Variáveis do Construto Qualidade da Informação (QUAINF)

\begin{tabular}{|l|l|l|}
\hline \multicolumn{1}{|c|}{ Variável } & \multicolumn{1}{|c|}{ Descrição } & Pergunta do Questionário \\
\hline $\begin{array}{l}\text { qiexatidão } \\
\text { (exatidão) }\end{array}$ & $\begin{array}{l}\text { Fidedignidade da informação } \\
\text { prestada ao usuário. }\end{array}$ & 1. As informações são exatas. \\
\hline $\begin{array}{l}\text { Qisegurança } \\
\text { (segurança) }\end{array}$ & $\begin{array}{l}\text { Percepção do usuário quanto à } \\
\text { confiabilidade no acesso e no } \\
\text { armazenamento da informação. }\end{array}$ & $\begin{array}{l}\text { 2. O controle de acesso garante } \\
\text { a segurança da informação. }\end{array}$ \\
\hline $\begin{array}{l}\text { qirelevância } \\
\text { (relevância) }\end{array}$ & $\begin{array}{l}\text { Percepção dos usuários quanto à } \\
\text { utilidade e aplicabilidade das } \\
\text { informações. }\end{array}$ & $\begin{array}{l}\text { 3. A informação prestada é } \\
\text { relevante. }\end{array}$ \\
\hline $\begin{array}{l}\text { Qifacilatendimento } \\
\text { (facil entendimento) }\end{array}$ & $\begin{array}{l}\text { Percepção do usuário em relação ao } \\
\text { grau de clareza e à ausência de } \\
\text { ambiguidade da informação. }\end{array}$ & $\begin{array}{l}\text { 4. O website disponível (www- } \\
\text { diadn) é amigável. }\end{array}$ \\
\hline $\begin{array}{l}\text { Qiatualização } \\
\text { (atualização) }\end{array}$ & $\begin{array}{l}\text { Grau de “modernidade" da informa- } \\
\text { ção relativo às necessidades daqueles } \\
\text { que a utilizam. }\end{array}$ & $\begin{array}{l}\text { 5. As informações solicitadas } \\
\text { são entregues atualizadas. }\end{array}$ \\
\hline $\begin{array}{l}\text { Qiintegridade } \\
\text { (integridade) }\end{array}$ & $\begin{array}{l}\text { Consistência e compatibilidade da } \\
\text { informação com seu histórico. }\end{array}$ & $\begin{array}{l}\text { 6. A informação é consistente } \\
\text { com a realidade. }\end{array}$ \\
\hline
\end{tabular}

Fonte: Elaborada pelos autores

Tabela 5: Variáveis do Construto Confiança (CONFIAN)

\begin{tabular}{|l|l|l|}
\hline \multicolumn{1}{|c|}{ Variável } & \multicolumn{1}{|c|}{ Descrição } & Pergunta do Questionário \\
\hline $\begin{array}{l}\text { cocredibilidade } \\
\text { (credibilidade) }\end{array}$ & $\begin{array}{l}\text { Percepção do usuário quanto à } \\
\text { veracidade e confiabilidade da } \\
\text { informação recebida. }\end{array}$ & $\begin{array}{l}\text { 7. A informação prestada pela } \\
\text { área de Administração de } \\
\text { Dados é confiável. }\end{array}$ \\
\hline $\begin{array}{l}\text { Coreputação } \\
\text { (reputação) }\end{array}$ & $\begin{array}{l}\text { Está associada a opinião do usuário } \\
\text { sobre a confiabilidade e a qualidade } \\
\text { dos serviços da área de Administra- } \\
\text { ção de Dados. }\end{array}$ & $\begin{array}{l}\text { 8. A área de Administração de } \\
\text { Dados possui reputação } \\
\text { positiva na percepção dos } \\
\text { analistas de TI. }\end{array}$ \\
\hline $\begin{array}{l}\text { cosoluçãoproblema } \\
\text { (solução de } \\
\text { problemas) }\end{array}$ & $\begin{array}{l}\text { Vincula-se à capacidade da área de } \\
\text { Administração de Dados para } \\
\text { solucionar problemas. }\end{array}$ & $\begin{array}{l}\text { 9. Os esclarecimentos prestados } \\
\text { contribuem para a solução de } \\
\text { problemas. }\end{array}$ \\
\hline $\begin{array}{l}\text { cocompetênciaprof } \\
\text { (competência } \\
\text { profissional) }\end{array}$ & $\begin{array}{l}\text { Capacitação profissional dos inte- } \\
\text { grantes da área de Administração de } \\
\text { Dados para orientar ou prestar } \\
\text { esclarecimentos ao usuário. }\end{array}$ & $\begin{array}{l}\text { 10. A área de Administração de } \\
\text { Dados demonstra competência } \\
\text { profissional quando orienta o } \\
\text { analista de TI }\end{array}$ \\
\hline $\begin{array}{l}\text { coatendimento } \\
\text { (atendimento) }\end{array}$ & $\begin{array}{l}\text { Percepção do usuário quanto às } \\
\text { características do relacionamento com } \\
\text { a área de Administração de Dados. }\end{array}$ & $\begin{array}{l}\text { 11. O atendimento prestado } \\
\text { pela equipe de Administração } \\
\text { de Dados atende a expectativa } \\
\text { (atitudes, valores éticos). }\end{array}$ \\
\hline
\end{tabular}

Fonte: Elaborada pelos autores 
Tabela 6: Variáveis do Construto Valor Percebido (VALPERC)

\begin{tabular}{|l|l|l|}
\hline \multicolumn{1}{|c|}{ Variável } & \multicolumn{1}{|c|}{ Descrição } & Pergunta do Questionário \\
\hline $\begin{array}{l}\text { vpreconhecimento } \\
\text { (reconhecimento) }\end{array}$ & $\begin{array}{l}\text { Reconhecimento, pela empresa, do } \\
\text { trabalho do usuário. }\end{array}$ & $\begin{array}{l}\text { 12. O trabalho do analista de TI } \\
\text { é reconhecido. }\end{array}$ \\
\hline $\begin{array}{l}\text { vpfundamental } \\
\text { (fundamental) }\end{array}$ & $\begin{array}{l}\text { Grau de importância da informação } \\
\text { colocada à disposição dos usuários. }\end{array}$ & $\begin{array}{l}\text { 13. O desempenho das ativida- } \\
\text { des do analista de TI é facilitado } \\
\text { pela informação. }\end{array}$ \\
\hline $\begin{array}{l}\text { Vpagregavalor } \\
\text { (agregação de } \\
\text { valor) }\end{array}$ & $\begin{array}{l}\text { Percepção do usuário quanto à } \\
\text { agregação de valor da informação. }\end{array}$ & $\begin{array}{l}\text { 14. As informações recebidas } \\
\text { elevam o valor do trabalho } \\
\text { realizado pelo analista de TI. }\end{array}$ \\
\hline
\end{tabular}

Fonte: Elaborada pelos autores

\section{Análise dos Resultados}

\subsection{Análise dos Dados}

O teste das estatísticas Z para amostra única de Kolmogorov-Smirnov registrou uma leve ocorrência de não normalidade com assimetria positiva em algumas das variáveis participantes na especificação do modelo, decorrente de uma concentração de respostas em torno das medidas 1 e 2 na escala métrica de Likert. Entretanto, os coeficientes de assimetria e de curtose indicaram normalidade ao nível de significância de 0,05; sendo assim, as variáveis são consideradas paramétricas, situação que propiciou a utilização das variáveis originais sem tratamento, na execução e nos testes do modelo. Os exames da ocorrência de linearidade e homocedasticidade para as variâncias latentes foram realizados graficamente. Hair (2005) sugere que as distribuições resultantes dos rebatimentos ortogonais do diagrama de dispersão entre pares de variáveis sejam normais. Não houve indícios da ocorrência de grau de assimetria significativo em qualquer dos eixos, no qual concluímos que as variâncias dos construtos foram constantes. Os pares de variáveis latentes foram ainda testados quanto à ausência de correlação, utilizando dados transformados de Fisher, hipóteses estas rejeitadas ao nível de significância de 0,05. 


\subsection{Análise Demográfica}

Dos 108 respondentes, 34\% estão lotados na matriz da Dataprev, localizada no Rio de Janeiro e os demais nas diversas unidades distribuídas pelo Brasil. Quanto ao tempo de atuação como usuário da área de administração de dados, 6,5\% dos entrevistados são usuários há no máximo dois anos, $38 \%$ são usuários entre dois e cinco anos, $22 \%$ entre cinco e dez anos e $33 \%$ acima de dez anos.

\subsection{Análise Exploratória}

O primeiro passo na análise dos dados coletados foi a avaliação da viabilidade da construção de um modelo, a partir da análise inicial exploratória dos resultados obtidos, com apoio do programa SPSS - Statistical Package for the Social Sciences, versão 15.0. O índice KMO de adequação da amostra para tratamento por análise fatorial é desejável que seja superior a 0,5 (MALHOTRA, 2006), neste caso, resultou em 0,905, superior ao piso desejável. O teste de esfericidade de Bartlett, por sua vez, rejeitou a hipótese de inexistência de covariância entre as variáveis, ao nível de significância de $5 \%$. Para verificar a confiabilidade do questionário estruturado, foram calculadas as estatísticas de Alfa de Cronbach para os três construtos da pesquisa, cujos resultados podem ser observados na Tabela 7:

Tabela 7: Estatísticas de Alfa de Cronbach

\begin{tabular}{|l|c|}
\hline \multicolumn{1}{|c|}{ Construto } & Alfa de Cronbach \\
\hline $\begin{array}{l}\text { Qualidade da Informação (QUAINF): exatidão, segurança, } \\
\text { relevância, fácil entendimento, atualização e integridade } \\
\text { (consistência). }\end{array}$ & 0,800 \\
\hline $\begin{array}{l}\text { Confiança (CONFIAN): credibilidade, reputação, solução de } \\
\text { problemas, competência profissional, atendimento. }\end{array}$ & 0,858 \\
\hline $\begin{array}{l}\text { Valor Percebido (VALPERC): reconhecimento, grau de impor- } \\
\text { tância, agregação de valor. }\end{array}$ & 0,815 \\
\hline
\end{tabular}

Fonte: Adaptado dos resultados gerados pelo Amos 


\subsection{Modelo de Equações Estruturais}

Os índices de ajustamento global foram calculados por intermédio do programa estatístico Amos 4.0, e estão sintetizados na Tabela 8 . O modelo é recursivo, superidentificado com 74 graus de liberdade. Em modelagem de equações estruturais, é comum que se avalie a razão $\chi^{2} / \mathrm{gl}$, uma vez que é o único teste de significância estatística desta ferramenta, embora sejam calculados vários outros índices de bondade de ajustamento. Os parâmetros são estimados de tal forma que seja mínima a discrepância entre a matriz de covariância da amostra e a matriz de covariância gerada pelo modelo. Quando a amostra é pequena, como a do presente estudo, pode haver restrição com a estatística $\chi^{2}$, pois esse teste é muito sensível ao tamanho da amostra. Sendo assim, recomenda-se a divisão do valor $\chi^{2}$ pelos graus de liberdade, adequando a sensibilidade do teste ao tamanho da amostra. No software Amos 4.0, essa razão é indicada como $\chi^{2} / \mathrm{gl}$.

Tabela 8: Estatísticas de Ajuste do Modelo Proposto

\begin{tabular}{|l|c|}
\hline \multicolumn{1}{|c|}{ Parâmetros } & Resultados \\
\hline $\begin{array}{l}\text { Variáveis Endógenas: } \\
\text { Observadas } \\
\text { Latentes }\end{array}$ & 14 \\
Variáveis Exógenas: \\
Latentes \\
$\quad$ Erros (residuais) & 2 \\
\hline Graus de Liberdade (gl) & 1 \\
\hline Qui-quadrado ( 2$)$ & 16 \\
\hline Qui-quadrado ajustado $\left(\left(\chi^{2} / g l\right)\right.$ & 74 \\
\hline GFI & 146,113 \\
\hline NFI & 1,975 \\
\hline IFI & 0,840 \\
\hline TLI & 0,828 \\
\hline CFI & 0,907 \\
\hline RMSEA & 0,883 \\
\hline
\end{tabular}

Fonte: Adaptado dos resultados gerados pelo Amos 
Na pesquisa do presente estudo, o valor resultante de 1,975 indica que o modelo hipotético não apresenta problema de ajustamento, pois, segundo Kline (1998), embora não haja uma regra universal que estabeleça um valor mínimo para a aceitação dessa razão, recomenda-se que somente devem ser considerados modelos, cuja razão $\chi^{2} / \mathrm{gl}$ seja inferior a três. O modelo proposto exibe índice de bondade de ajustamento (GFI - Goodness-of-Fit Index) de 0,84 , indicando nível satisfatório de ajustamento, uma vez que se situa acima de 0,80.O índice de ajuste incremental (IFI - Incremental Fit Index), o de Tucker-Lewis (TLI - Tucker-Lewis Index), o de adequação do índice de ajuste (NFI - Normal Fit Index) e o de ajuste comparativo (CFI - Comparative Fit Index) também apresentaram valores em torno daqueles recomendados na literatura. Para um valor recomendado do RMSEA (Root Mean Square Error of Approximation) inferior a 0.08, que indica erro razoável de aproximação, o índice de 0,095 atesta um ajustamento aceitável, uma vez que é inferior ao limite superior de 0,10 , acima do qual não se recomenda o emprego do modelo hipotético.

A partir desta primeira avaliação, conclui-se que o modelo proposto apresenta ajustamento global aceitável. Todavia, não basta investigar apenas esse aspecto do modelo, uma vez que é preciso que os pesos estruturais apresentem não apenas os sinais esperados, como também sejam estatisticamente significativos. O modelo não exibiu nenhum peso de regressão com sinal negativo, conforme esperado. A Tabela 9 permite estabelecer uma avaliação mais detalhada das estimativas dos parâmetros, uma vez que demonstra as significâncias estatísticas. O software Amos 4.0 testa a significância estatística do parâmetro pela razão crítica, da forma como é realizada para o cálculo da estatística t, ou seja, verifica-se se a estimativa do peso de regressão é diferente de zero a determinado nível de significância. Isso quer dizer que, se a razão crítica da estimativa superar o módulo |1,96|, pode-se rejeitar a hipótese de que a estimativa seja igual a zero, neste caso, ao nível de significância de 5\%. Assim, o caminho apresenta peso de regressão estatisticamente significativo, possibilitando sua aceitação e, por conseguinte, a confirmação da hipótese a ele associada. 
Tabela 9: Pesos de Regressão

\begin{tabular}{|c|c|c|c|c|}
\hline \multicolumn{2}{|c|}{ Caminho } & Estimativa & Razão & Resultado \\
\hline valor percebido & qualidade $\quad$ (H1) & 1,022 & 6,779 & Aceita \\
\hline confiança & valor percebido (H2) & 0,661 & 2,543 & Aceita \\
\hline confiança & qualidade & 0 & 0,899 & Rejeitada \\
\hline qiexatidão & qualidade & 1,000 & & Aceita \\
\hline qisegurança & qualidade & 0,735 & 4,072 & Aceita \\
\hline qirelevância & qualidade & 1,157 & 6,914 & Aceita \\
\hline qifacilentendimento & qualidade & 0,860 & 5,024 & Aceita \\
\hline qiatualização & qualidade & 1,095 & 6,342 & Aceita \\
\hline qiintegridade & qualidade & 1,191 & 7,097 & Aceita \\
\hline coatendimento & confiança & 1,000 & & Aceita \\
\hline cocompetênciaprof & confiança & 1,010 & 7,540 & Aceita \\
\hline cosoluçãoproblema & confiança & 1,138 & 7,832 & Aceita \\
\hline coreputação & confiança & 1,173 & 7,545 & Aceita \\
\hline cocredibilidade & confiança & 1,132 & 7,403 & Aceita \\
\hline vpreconhecimento & valor percebido & 1,000 & & Aceita \\
\hline vpfundamental & valor percebido & 1,025 & 7,964 & Aceita \\
\hline vppagregavalor & valor percebido & 0,945 & 8,603 & Aceita \\
\hline
\end{tabular}

Fonte: Adaptado da matriz gerada pelo software Amos

Das hipóteses formuladas neste estudo, apenas uma foi rejeitada, aquela na qual a variável latente Confiança é influenciada direta e positivamente pela variável latente Qualidade da Informação, uma vez que a razão crítica é inferior a 1,96. No entanto, a variável Confiança é influenciada indireta e positivamente pela variável Qualidade da Informação, mediada pelo Valor Percebido, uma vez que as hipóteses $\mathrm{H}_{1}$ e $\mathrm{H}_{2}$ foram confirmadas. Pode-se entender esse resultado a partir de um dos conceitos anteriormente comentados: "Para a informação ser percebida como valiosa e utilizada com confiança, deve ser exata [...]" (DAVENPORT, 1998, p. 252), ou seja, a exatidão reflete sua qualidade, a qual uma vez confirmada passa a ser percebida como possuidora de valor, e assim consolida o nível de confiança do usuário.

No caso da Dataprev, uma situação que confirma tal fato e, consequentemente, cria credibilidade no usuário, é a validação e o teste do Modelo de Dados (produto do seu trabalho em conjunto com a equipe de Administração de Dados) pelos clientes. Portanto, o usuário apenas terá con- 
fiança na informação prestada pela área de Administração de Dados, quando ela for percebida como válida, tornando-se, então, crível para uso pelo cliente (BARRETO, 1994).

O construto QUAINF, cujo peso de regressão é 1,022, com razão crítica de 6,779, é o mais importante do modelo, em função não apenas da magnitude superior, mas também porque impacta o construto CONFIAN indiretamente por meio do construto VALPERC. No construto QUAINF, as variáveis que apresentaram maior peso de regressão foram qiintegridade (consistência e compatibilidade da informação com seu histórico) e qirelevância (percepção dos usuários quanto à utilidade e à aplicabilidade das informações). No caso da variável qiintegridade, esse resultado indica quanto os usuários estão preocupados com a consistência da informação recebida: suas decisões são tomadas a partir dessas informações e, caso estejam incompletas ou inconsistentes, comprometerão suas decisões o que, muitas vezes, pode levar a prejuízos irreparáveis. Quanto à variável qirelevância, o resultado evidencia quando a informação chega de forma ambígua, de difícil compreensão ou em quantidade desnecessária (sobrecarga de informações). Dessa forma, o usuário tem dificuldade em utilizá-la e possivelmente o fará de forma incorreta, ocasionando, com isso, "retrabalhos" e atrasos.

No construto CONFIAN, a variável de maior peso foi coreputacao (opinião do usuário sobre a confiabilidade e a qualidade dos serviços da área de Administração de Dados). Esse resultado vem corroborar a opinião dos diversos autores apresentados neste estudo, a exemplo de Granovetter (1985), quando afirma que a fonte de confiança está em estabelecer relações com pessoas e organizações de reconhecida reputação. Quanto ao construto VALPERC, todas as variáveis apresentaram valores significativos, sendo a vpfundamental (grau de importância das informações colocadas à disposição dos usuários) a de maior relevância. Tal constatação não surpreende, uma vez que as atividades do usuário são realizadas com o apoio da informação que recebe. Quanto mais relevante for ela para o usuário, maior seu grau de contribuição na execução das atividades e maior a percepção de valor.

\section{Considerações Finais}

O ponto central deste estudo foi avaliar a consistência do modelo proposto, o qual supõe que a qualidade e o valor percebido da informação 
impactam positivamente na confiança dos usuários da área de Administração de Dados. Os resultados dos testes empíricos conduzidos por outros estudos indicam haver relação entre tais construtos. A confiança é construída a partir das experiências bem-sucedidas que impactam positivamente na qualidade percebida da informação. Do mesmo modo, tal relação de "causalidade" é complementada por meio da mediação do valor percebido, decorrente dos benefícios intrínsecos e extrínsecos construídos no decorrer do processo de relacionamento.

Tais resultados, que acabam por criar indícios teóricos de traços atitudinais de comportamento do usuário, foram verificados no teste de validação empírica conduzido pelo presente estudo. Nesse caso, informações geradas no ambiente da Dataprev, foram testadas quanto ao grau de confiança manifestado pelo usuário. Constatou-se que a qualidade e o valor percebido representaram fortes elementos de "causalidade" na construção de vínculos de confiança. O trabalho empírico demonstrou ser a qualidade da informação, o construto antecedente que exerce a maior influência sobre o valor percebido, sendo que este último atuou como construto mediador para com a confiança relativa ao uso da informação, conclusões estas obtidas a partir da análise de significância dos parâmetros da regressão. Portanto, os resultados do estudo comprovaram a existência do elo causal proposto pela literatura examinada, mesmo com a rejeição da hipótese H3 (a Confiança é influenciada direta e positivamente pela Qualidade da Informação), tendo em conta as peculiaridades da Dataprev.

Outro aspecto importante decorreu da confirmação da adequação da metodologia aplicada a questões que envolvam relações causais entre variáveis latentes. Os resultados apresentados pela Modelagem de Equações Estruturais permitiram a conclusão de que esta é uma ferramenta adequada de análise multivariada nesta situação.

Uma possível extensão desse estudo sugere que a análise seja ampliada para usuários externos, a exemplo dos demais órgãos públicos da esfera federal, uma vez que o valor percebido, manifestado na dimensão do sacrifício monetário incorrido pelo usuário final não é característica dos usuários intermediários, internos, da Dataprev. 


\section{The User Trust on the Data Management of Dataprev}

\section{Abstract}

The quality of the information has caused an increasing interest among business researchers, as far as information is a key tool in decision making for all corporate levels. Therefore, it is recommended to think on its concept not as a mean, usually, but as a product instead. In this research it is emphasized the managers need for indicators in order to make it feasible evaluate how information is perceived regarding the way it is used, its worth and its reliability. Thus, the objective of this research is to verify whether the internal user trust is influenced by the information quality and perceived value, as provided by the Data Management office. The survey was conducted in Dataprev, a public owned company in charge of performing information technology for the Brazilian social security. Data from a non-random sample of 108 respondents was collected by means of a structured questionnaire containing 14 questions measured by a five points Likert scale, which were treated by a Structured Equations Model (SEM). It was found that the construct Information Quality is a relevant antecedent for the Perceived Value which, in its turn, mediates the Trust on information. Moreover, it was confirmed the adequacy of SEM in aspects involving causal relationships among latent variables.

Key words: Information Quality. Reliability. Corporate Management.

\section{Referências}

ANDERSON, J. C.; NARUS, J. A. Business Marketing: understanding what customers value. Harvard Business Review, v. 76, n. 6, p. 53-65, 1998.

BARBIERI, C. BI - Business Intelligence. Rio de Janeiro: Axcel Books, 2001.

BARRETO, A. A Questão da Iinformação. São Paulo em Perspectiva, São Paulo: Fundação Seade, v. 8, n. 4, 1994.

. A oferta e a demanda da informação: condições técnicas, econômicas

e políticas. Ciência da Informação, v. 32, n. 2, Brasília, 1999. 
COLEMAN, J. S. Foundations of Social Theory. Cambridge: Harvard University Press, 1990.

DAVENPORT, T. H. Ecologia da Informação: porque só a tecnologia não basta na era da informação. São Paulo: Futura, 1998.

DOLL, W. J.; TORKZADEH, G. The Measurement of End-User Computing Satisfaction. MIS Quarterly, v. 12, p. 259-274, 1998.

\section{ENGLISH, L. Data Warehouse and Business Information Quality.} Toronto: Wiley, 1999.

GALE, B. T. Customer Value Analysis Sheds Light on Consumers' Needs. Corporate University Review, v. 8, n. 3, p. 9-10, may/june, 2000a. . Trends in Customer Satisfaction, Loyalty, and Value. Customer Value, Inc., p. 1-11, 2000 b.

GRANOVETTER, M. Economic Action and Social Structure: the problem of the embeddedness. American Journal of Sociology, v. 91, p. 481-510, 1985.

GRONROOS, C. Marketing: gerenciamento de serviços. Rio de Janeiro: Elsevier, 2003.

HAIR, J. J. F. et al. Análise Multivariada de Dados. Porto Alegre: Bookman, 2005.

HARDIN, R. Conceptions and Explanations of Trust. Nova York: Cook, Karen, 2001.

KLINE, R. B. Principles and Practice of Structural Equation Modeling. New York: Guilford Press, 1998.

MALHOTRA, N. Pesquisa de Marketing: uma orientação aplicada. Porto Alegre: Bookman, 2006.

MCGEE, J.; PRUSAK, L. Gerenciamento Estratégico da Informação. Rio de Janeiro: Campus, 1994.

MOWEN, J. C.; MINOR, M. S. Comportamento do Consumidor. São Paulo: Pearson, 2003. 
OLIVER, R. L. Whence Consumer Loyalty? Journal of Marketing, Special Issue, v. 63, n. 4, p. 33-44, october, 1999.

PARASUMARAN, A.; ZEITHAML, V.A.; BERRY, L. L. SERVQUAL: a multipleitem scale for measuring consumer perceptions of service quality. Journal of Retailing, v. 64, p. 12-40, 1988.

RAVALD, A.; GRÖNROOS, C. The Value Concept and Relationship Marketing. European Journal of Marketing, v. 30, n. 2, p. 19-30, 1996.

RIBAS, J. R.; VIEIRA, P. R. C. Análise Multivariada com o Uso do SPSS. Rio de Janeiro: Ciência Moderna, 2011.

SEBERA, D.; TAN, F. User Satisfaction: an overarching measure of enterprise system success. In: PACIFIC ASIA CONFERENCE ON INFORMATION SYSTEM, 2005. Anais... Bangkok: PACIS, 2005.

SHEPPARD, B. H.; SHERMAN, D. M. The Grammars of Trust: a model and general implications. Academy of Management Review, v. 23, n. 3, p. 422437, 1998.

SCHREIBER, J. B. et al. The Journal of Educational Research, v. 99, n. 6, p. 323-337, 2006.

STEWART, T. A. Capital Intelectual: a nova vantagem competitiva das empresas. Rio de Janeiro: Campus, 1998.

TURBAN, E.; RAINER J. R. K.; POTTER, R. E. Administração de Tecnologia da Informação: teoria e pratica. Rio de Janeiro: Campus, 2003.

. KING, D.; MCKAY, J.; LEE, J. Electronic Commerce: a managerial perspective. 4th ed., Upper Saddle River: Prentice Hall, 2006.

WANG, R.Y; LEE, Y. L; HUANG, K. Quality Information and Knowledge Management. Upper Saddle River: Prentice-Hall, 1998.

. A Product Perspective on Total Data Quality Management.

Communications of the ACM, v. 41, n. 2, 1998. 